\title{
State Medicaid Eligibility and Care Delayed Because of Cost
}

\section{Citation}

Clark, Cheryl R., Mark J. Ommerborn, Brent A. Coull, Do Quyen Pham, and Jennifer Haas. 2013. "State Medicaid Eligibility and Care Delayed Because of Cost." New England Journal of Medicine 368 (13) (March 28): 1263-1265. doi:10.1056/nejmc1214874.

\section{Published Version}

doi:10.1056/NEJMc1214874

\section{Permanent link}

http://nrs.harvard.edu/urn-3:HUL.InstRepos:37135340

\section{Terms of Use}

This article was downloaded from Harvard University's DASH repository, and is made available under the terms and conditions applicable to Other Posted Material, as set forth at http:// nrs.harvard.edu/urn-3:HUL.InstRepos:dash.current.terms-of-use\#LAA

\section{Share Your Story}

The Harvard community has made this article openly available.

Please share how this access benefits you. Submit a story.

\section{Accessibility}


can Physicians and Surgeons showing that 93.7\% of respondents voted to abolish MOC requirements. In its place, Mandel proposes a limited trial to test the value of MOC secure examinations, an exercise that would leave in limbo some 450,000 physicians who are actively involved in MOC through 24 specialty boards. Our article quotes Wachter, who makes a valid argument that, in the face of multiple competing efforts to judge physician performance, such a vacuum would be risky because if MOC went away, "it would be quickly replaced by more regulatory external bodies that ultimately would be more burdensome to physicians" and would not be led by them. To some extent, three varying views of MOC published in the Journal reinforce Wachter's opinion. One editorial said: "The experts for and against MOC agree that the concept of recertification is sound - what they disagree about is the process." ${ }^{\prime}$

As Norris and Nora emphasize, the ABMS is mindful of the criticisms of the current MOC and is committed, along with its specialty boards, to ongoing improvement of MOC as outlined in a 2012-2015 strategic plan approved by the board of the ABMS. ${ }^{2}$ The plan calls for more extensive researching of the impact of MOC on the quality of care, increasing the value of MOC to participating physicians, and integrating MOC more effectively into the practice environment. To this end, the boards plan to solicit direct feedback from physicians on MOC and implement a program that would engage physicians in local improvement projects to satisfy MOC practiceassessment requirements.

John K. Iglehart

Robert B. Baron, M.D.

University of California, San Francisco

San Francisco, CA

Since publication of their article, the authors report no further potential conflict of interest.

1. Drazen JM, Weinstein DF. Considering recertification. N Engl J Med 2010;362:946-7.

2. ABMS 2012-2015 strategic plan as approved by the ABMS board of directors. Chicago: American Board of Medical Specialties, September 20, 2011.

DOI: 10.1056/NEJMc1301026

\section{State Medicaid Eligibility and Care Delayed Because of Cost}

TO THE EDITOR: Provisions of the Patient Protection and Affordable Care Act (ACA) are expected to reduce the number of adults who delay seeking needed medical care because of cost. ${ }^{1}$ Reforms are expected to improve the ability to obtain care, in part, by extending Medicaid access to adults with incomes at or below $133 \%$ of the federal poverty line. ${ }^{2}$ A recent Supreme Court ruling gave greater latitude to state approaches to Medicaid expansion. ${ }^{3}$ Various state strategies for implementing reforms may amplify geographic variation in the prevalence of delayed care. Estimating the existing variation in and correlates of delayed care may assist states that are planning to improve access within and beyond the framework provided by the ACA.

We examined county-level geographic variation in the prevalence of care delayed because of cost among 289,333 adults who were 18 to 64 years of age in the 2010 Behavioral Risk Factor Surveillance System (BRFSS) survey, a state-based telephone survey of health care access and health status. We calculated smoothed county-level prev- alence estimates of delayed care using generalized linear mixed models. ${ }^{4}$ We examined the relationship between Medicaid eligibility thresholds for working adults with children and the odds that the BRFSS survey participants would delay seeking care. Statistical models were adjusted for the participants' sociodemographic and clinical characteristics and for the characteristics of the state and local health care infrastructure. $^{5}$

As shown in Figure 1, the county-level prevalence of delayed care ranged from $6.5 \%$ in Norfolk, Massachusetts, to $40.6 \%$ in Hidalgo, Texas. More restrictive Medicaid eligibility criteria were associated with a higher prevalence of delayed care than that observed when eligibility criteria were set at or above $133 \%$ of the federal poverty line. For example, the increased odds of delayed care was $16 \%$ as high among persons with incomes between 67 and $127 \%$ of the federal poverty line and $42 \%$ as high among persons with incomes between 17 and 44\% of the federal poverty line. In addition, a higher concentration 


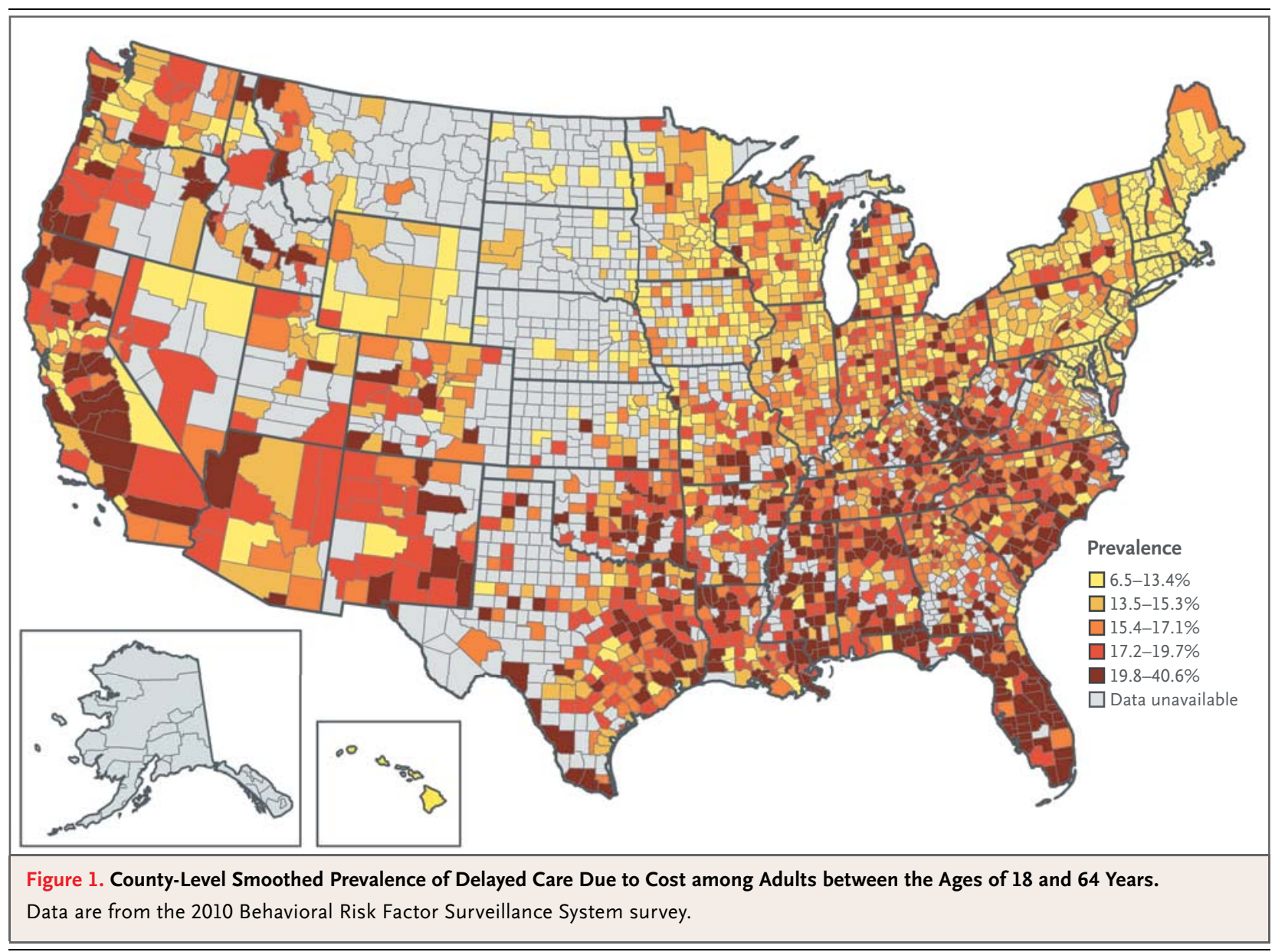

of primary care doctors was associated with a lower prevalence of delayed care (see Table 1 in the Supplementary Appendix, available with the full text of this letter at NEJM.org). We reviewed data on the prevalence of delayed care in six counties in areas with different strategies for management of the health care infrastructure. Table 2 in the Supplementary Appendix shows that populations in counties with the highest prevalence of delayed care were more likely to be Hispanic and have low incomes and a high prevalence of chronic disease, and these areas had a relatively late history of state Medicaid expansion.

Our results suggest stark geographic differences in the prevalence of care delayed because of cost. Particularly vulnerable areas were in the South, including Texas and Florida. States and counties with a high prevalence of delayed care had a weaker health care infrastructure than states with a lower prevalence of delayed care.
Since states determine strategies for implementing the ACA, areas with a high prevalence of delayed care should monitor their progress with the use of the BRFSS survey and other data sources. These states may require additional investments to "catch up" to places with a stronger infrastructure.

Cheryl R. Clark, M.D., Sc.D.

MarkJ. Ommerborn, M.P.H.

Brigham and Women's Hospital

Boston, MA

Brent A. Coull, Ph.D.

Harvard School of Public Health Boston, MA

Do Quyen Pham, M.P.H. Jennifer Haas, M.D.

Brigham and Women's Hospital Boston, MA

jhaas@partners.org 
Supported by grants from the National Institute on Aging (K08 AG 032357) and from the National Institutes of Health (UL1 RR 025758-01) and by financial contributions from participating institutions of the Harvard Clinical and Translational Science Center.

Disclosure forms provided by the authors are available with the full text of this letter at NEJM.org.

1. The uninsured and the difference health insurance makes. Washington, DC: Kaiser Commission on Medicaid and the Uninsured, 2012 (http://www.kff.org/uninsured/upload/1420-14.pdf). 2. Connors EE, Gostin LO. Health care reform - a historic moment in US social policy. JAMA 2010;303:2521-2.

3. Rosenbaum S, Westmoreland TM. The Supreme Court's surprising decision on the Medicaid expansion: how will the federal government and states proceed? Health Aff (Millwood) 2012;31:1663-72.

4. Modelling areal data. In: Bivand RS, Pebesma EJ, GómezRubio V. Applied spatial data analysis with R. New York: Springer, 2008:273-310.

5. Carle AC. Fitting multilevel models in complex survey data with design weights: Recommendations. BMC Med Res Methodol 2009;9:49.

DOI: 10.1056/NEJMc1214874

Correspondence Copyright @) 2013 Massachusetts Medical Society.

INSTRUCTIONS FOR LETTERS TO THE EDITOR

Letters to the Editor are considered for publication, subject to editing and abridgment, provided they do not contain material that has been submitted or published elsewhere. Please note the following:

- Letters in reference to a Journal article must not exceed 175 words (excluding references) and must be received within 3 weeks after publication of the article.

- Letters not related to a Journal article must not exceed 400 words.

- A letter can have no more than five references and one figure or table.

- A letter can be signed by no more than three authors.

- Financial associations or other possible conflicts of interest must be disclosed. Disclosures will be published with the letters. (For authors of Journal articles who are responding to letters, we will only publish new relevant relationships that have developed since publication of the article.)

- Include your full mailing address, telephone number, fax number, and e-mail address with your letter.

- All letters must be submitted at authors.NEJM.org.

Letters that do not adhere to these instructions will not be considered. We will notify you when we have made a decision about possible publication. Letters regarding a recent Journal article may be shared with the authors of that article. We are unable to provide prepublication proofs. Submission of a letter constitutes permission for the Massachusetts Medical Society, its licensees, and its assignees to use it in the Journal's various print and electronic publications and in collections, revisions, and any other form or medium.

\section{CORRECTION}

Endovascular Therapy after Intravenous t-PA versus t-PA Alone for Stroke (March 7, 2013;368:893-903). At the top of Figure 2 (page 899), "Relative Risk ( $95 \% \mathrm{CI}$ )" should have been "Relative Risk $(99 \%$ CI)." The article is correct at NEJM.org.

\section{NOTICES}

Notices submitted for publication should contain a mailing address and telephone number of a contact person or department. We regret that we are unable to publish all notices received. Notices also appear on the Journal's website (NEJM.org/medical-conference). The listings can be viewed in their entirety or filtered by specialty, location, or month.

\section{MINDFUL PRACTICE: FOCUS ON SERIOUS \\ AND LIFE-LIMITING ILLNESS}

The workshop will be held in Batavia, NY, May 1-4. It is sponsored by the University of Rochester Department of Family Medicine and Center for Experiential Learning.

Contact the University of Rochester Center for Experiential Learning, 601 Elmwood Ave., Box 709, Rochester, NY 14642; or call (585) 275-4392; or see http://www.urmc.rochester.edu/cpe.

\section{SOCIETY OF LAPAROENDOSCOPIC SURGEONS}

The following meetings will be held: "Minimally Invasive Surgery Week: Annual Meeting \& Endo Expo 2013" (Reston, VA, Aug. 28-31) and "AsianAmerican MultiSpecialty Summit VI: Laparoscopy \& Minimally Invasive Surgery” (Honolulu, HI, Feb. 12-15).

Contact the Society of Laparoendoscopic Surgeons, 7330 SW 62nd Place, Suite 410, Miami, FL 33143; or call (305) 665-9959; or fax (305) 667-4123; or see http://www.sls.org.

\section{MAYO CLINIC}

The following meetings will be held in Rochester, MN: "Advanced Techniques in Shoulder Arthroscopy, Arthroplasty \& Fractures" (April 26 and 27); "34th Annual Practice of Internal Medicine" (April 29-May 3); "Commercial Driver Medical Examiner Training” (April 26, May 17, June 7); "Mayo Clinic General Thoracic Surgery Symposium" (May 3); "5th Annual Hospital Medicine for Nurse Practitioners and Physician Assistants" (May 15-17); "Mayo Clinic Clinical Autonomic Quantitation Workshop" (May 17-19); "20th Annual Nicotine Dependence Conference" (May 20 and 21); "Disorders of the Wrist" (May 24-26); "Mayo Clinic 10th Annual EUS Summit" (Aug. 1-3); and "Mucha Symposium on Acute Care and Trauma Surgery" (Aug. 8 and 9).

Contact the Mayo School of Continuous Professional Development, 200 First St. SW, Rochester, MN 55905; or call (800) 323-2688 or (507) 284-2509; or fax (507) 284-0532; or see http://www.mayo.edu/cme; or e-mail cme@mayo.edu.

IDWEEK 2013: ADVANCING SCIENCE, IMPROVING CARE

The meeting will be held in San Francisco, Oct. 2-6. It is jointly presented by the Infectious Diseases Society of America (IDSA), the Society for Healthcare Epidemiology of America (SHEA), the HIV Medicine Association (HIVMA), and the Pediatric Infectious Diseases Society (PIDS).

Contact Dana Johnston, IDWeek, 1300 Wilson Blvd., Suite 300, Arlington, VA 22209; or call (703) 740-4961; or e-mail info@idweek.org; or see http://www.idweek.org.

\section{AMERICAN SOCIETY OF TROPICAL MEDICINE AND HYGIENE}

The "ASTMH 62nd Annual Meeting" will be held in Washington, DC, Nov. 13-17. Deadline for submission of travel award applications is April 3. Deadline for submission of abstracts is May 2.

Contact the American Society of Tropical Medicine and Hygiene, 111 Deer Lake Rd., Suite 100, Deerfield, IL 60015; or call (847) 480-9592; or fax (847) 480-9282; or see http://www.astmh .org. 